\title{
Rapid-cycling bipolar disorder: cross-national community study
}

Sing Lee, Adley Tsang, Ronald C. Kessler, Robert Jin, Nancy Sampson, Laura Andrade, Elie G. Karam, Maria Elena Medina Mora, Kathleen Merikangas, Yoshibumi Nakane, Daniela Georgeta Popovici, Jose Posada-Villa, Rajesh Sagar, J. Elisabeth Wells, Zahari Zarkov and Maria Petukhova

\section{Background}

The epidemiology of rapid-cycling bipolar disorder in the community is largely unknown.

\begin{abstract}
Aims
To investigate the epidemiological characteristics of rapidcycling and non-rapid-cycling bipolar disorder in a large cross-national community sample.
\end{abstract}

\section{Method}

The Composite International Diagnostic Interview (CIDI version 3.0) was used to examine the prevalence, severity, comorbidity, impairment, suicidality, sociodemographics, childhood adversity and treatment of rapid-cycling and nonrapid-cycling bipolar disorder in ten countries $(n=54257)$.

\section{Results}

The 12-month prevalence of rapid-cycling bipolar disorder was $0.3 \%$. Roughly a third and two-fifths of participants with lifetime and 12-month bipolar disorder respectively met criteria for rapid cycling. Compared with the nonrapid-cycling, rapid-cycling bipolar disorder was associated with younger age at onset, higher persistence, more severe depressive symptoms, greater impairment from depressive symptoms, more out-of-role days from mania/ hypomania, more anxiety disorders and an increased likelihood of using health services. Associations regarding childhood, family and other sociodemographic correlates were less clear cut.

\section{Conclusions}

The community epidemiological profile of rapid-cycling bipolar disorder confirms most but not all current clinically based knowledge about the illness.

\section{Declaration of interest}

R.C.K. has been a consultant for GlaxoSmithKline Inc, Kaiser Permanente, Pfizer Inc, Sanofi-Aventis, Shire Pharmaceuticals and Wyeth-Ayerst; has served on advisory boards for Eli Lilly \& Company and Wyeth-Ayerst; and has had research support for his epidemiological studies from Bristol-Myers Squibb, Eli Lilly \& Company, GlaxoSmithKline, Johnson \& Johnson Pharmaceuticals, Ortho-McNeil Pharmaceuticals Inc, Pfizer Inc and Sanofi-Aventis.
Since its first description in $1974,{ }^{1}$ rapid-cycling bipolar disorder has been shown to be present in about $12-24 \%$ of people with bipolar disorders at specialised mood disorder clinics in Western countries. Compared with non-rapid-cycling bipolar disorder, it is more common in females, associated with earlier age at onset, greater illness burden and relatively higher treatment resistance. $^{2-5}$ Nonetheless, a number of nosological and clinical issues about rapid-cycling bipolar disorder have remained unresolved. These include whether it is an iatrogenic condition, ${ }^{6}$ an arbitrary entity in a dimensional framework of conceptualising episode frequency in bipolar disorder ${ }^{5,7,8}$ and, more generally, whether current knowledge about this disorder is biased by a higher probability of help-seeking that accompanies Western patients with severe rapid-cycling mood episodes.

There has been no community-based epidemiological study to clarify the above issues from a cross-national perspective. ${ }^{3}$ This may be because it is difficult for lay interviewers to obtain precise data on the nuances of onset and offset of mood episodes in community samples using currently available structured diagnostic instruments. Another reason could be the need for a large representative sample to estimate the possibly very low prevalence of rapid-cycling bipolar disorder in the community. The World Mental Health version of the Composite International Diagnostic Interview (WMH-CIDI) ${ }^{9}$ allows us to create an epidemiological measure of rapid-cycling bipolar disorder that approximates the DSM-IV definition of the disorder. ${ }^{10}$ This paper presents the first general population study of the prevalence and correlates of rapid-cycling bipolar disorder based on a large data-set from ten socioeconomically diverse countries of the World Mental Health Survey Initiative (www.hcp.med. harvard.edu/wmh/).

\section{Method}

\section{Participants}

Ten surveys were carried out in the Americas (São Paulo metropolitan area in Brazil, Colombia, Mexico, USA), Europe (Bulgaria, Romania) and Asia (Pondicherry region in India, nine metropolitan areas in Japan, Lebanon, New Zealand). Except in Japan (unclustered two-stage probability sample), they were all based on stratified multistage clustered area probability samples. Interviews were carried out face to face by trained lay interviewers on household residents ages 18 and older (except $\geqslant 16$ years in New Zealand and $\geqslant 20$ years in Japan). Sample sizes ranged from 2357 (Romania) to 12790 (New Zealand). Response rates ranged from $59.2 \%$ (Japan) to $98.8 \%$ (India), with an average of $74.4 \%$ (Table 1).

\section{Procedures}

In each country, survey supervisors who were fluent in English and their local languages were trained by experienced CIDI trainers in the USA on the use of the survey instrument and procedures. They were also involved in translation of the instrument and training materials for interviewers in their survey sites according to the translation protocol of the World Health Organization. ${ }^{11}$ Surveys were carried out exclusively in the official languages of the countries. Individuals who could not speak 


\begin{tabular}{|c|c|c|c|c|c|c|c|c|}
\hline \multirow[b]{2}{*}{ Country } & \multirow[b]{2}{*}{ Survey } & \multirow[b]{2}{*}{ Sample characteristics ${ }^{a}$} & \multirow[b]{2}{*}{$\begin{array}{l}\text { Field } \\
\text { dates }\end{array}$} & \multirow{2}{*}{$\begin{array}{l}\text { Age } \\
\text { range } \\
\text { years }\end{array}$} & \multicolumn{3}{|c|}{ Sample size, $n$} & \multirow[b]{2}{*}{$\begin{array}{l}\text { Response } \\
\text { rate }^{c}\end{array}$} \\
\hline & & & & & Part 1 & Part 2 & $\begin{array}{l}\text { Part } 2 \text { and } \\
\text { age } \leqslant 44^{b}\end{array}$ & \\
\hline Brazil & $\begin{array}{l}\text { São Paulo } \\
\text { megacity }\end{array}$ & $\begin{array}{l}\text { Stratified multistage clustered area probability sample of } \\
\text { household residents in the São Paulo metropolitan area. }\end{array}$ & $2005-7$ & $18+$ & 5037 & 2942 & - & 81.3 \\
\hline Bulgaria & NSHS & $\begin{array}{l}\text { Stratified multistage clustered area probability sample of } \\
\text { household residents. NR. }\end{array}$ & $2003-7$ & $18+$ & 5318 & 2233 & 741 & 72.0 \\
\hline Colombia & $\mathrm{NSMH}$ & $\begin{array}{l}\text { Stratified multistage clustered area probability sample of } \\
\text { household residents in all urban areas of the country } \\
\text { (approximately } 73 \% \text { of the total national population) }\end{array}$ & 2003 & $18-65$ & 4426 & 2381 & 1731 & 87.7 \\
\hline India & WMHI & $\begin{array}{l}\text { Stratified multistage clustered area probability sample of } \\
\text { household residents in Pondicherry region. NR }\end{array}$ & $2003-5$ & $18+$ & 2992 & 1373 & 642 & 98.8 \\
\hline Japan & $\begin{array}{l}\text { WMHJ20 } \\
02-2006\end{array}$ & $\begin{array}{l}\text { Un-clustered two-stage probability sample of individuals } \\
\text { residing in households in nine metropolitan areas (Fukiage, } \\
\text { Higashi-ichiki, Ichiki, Kushikino, Nagasaki, Okayama, Sano, } \\
\text { Tamano, and Tendo) }\end{array}$ & $2002-6$ & $20+$ & 3417 & 1305 & 425 & 59.2 \\
\hline Lebanon & LEBANON & $\begin{array}{l}\text { Stratified multistage clustered area probability sample } \\
\text { of household residents. NR. }\end{array}$ & $2002-3$ & $18+$ & 2857 & 1031 & 595 & 70.0 \\
\hline Mexico & M-NCS & $\begin{array}{l}\text { Stratified multistage clustered area probability sample } \\
\text { of household residents in all urban areas of the country } \\
\text { (approximately } 75 \% \text { of the total national population). }\end{array}$ & $2001-2$ & $18-65$ & 5782 & 2362 & 1736 & 76.6 \\
\hline New Zealand ${ }^{d}$ & NZMHS & $\begin{array}{l}\text { Stratified multistage clustered area probability sample } \\
\text { of household residents. NR. }\end{array}$ & $2004-5$ & $18+$ & 12790 & 7312 & 4119 & 73.3 \\
\hline Romania & RMHS & $\begin{array}{l}\text { Stratified multistage clustered area probability sample } \\
\text { of household residents. NR. }\end{array}$ & $2005-6$ & $18+$ & 2357 & 2357 & - & 70.9 \\
\hline USA & NCS-R & $\begin{array}{l}\text { Stratified multistage clustered area probability sample } \\
\text { of household residents. NR. }\end{array}$ & $2002-3$ & $18+$ & 9282 & 5692 & 3197 & 70.9 \\
\hline \multicolumn{9}{|c|}{$\begin{array}{l}\text { NSHS, Bulgaria National Survey of Health and Stress; NR, nationally representative; NSMH, The Colombian National Study of Mental Health; WMHI, World Mental Health India; } \\
\text { WMHJ2002-2006, World Mental Health Japan Survey; LEBANON, Lebanese Evaluation of the Burden of Ailments and Needs of the Nation; M-NCS, The Mexico National Comorbidity } \\
\text { Survey; NZMHS (New Zealand Mental Health Survey; RMHS, Romania Mental Health Survey; NCS-R, The US National Comorbidity Survey Replication. } \\
\text { a. Most World Mental Health surveys are based on stratified multistage clustered area probability household samples in which samples of areas equivalent to counties or } \\
\text { municipalities in the USA were selected in the first stage followed by one or more subsequent stages of geographic sampling (e.g. towns within counties, blocks within towns, } \\
\text { households within blocks) to arrive at a sample of households, in each of which a listing of household members was created and one or two people were selected from this listing } \\
\text { to be interviewed. No substitution was allowed when the originally sampled household resident could not be interviewed. These household samples were selected from Census area } \\
\text { data in all countries. The Japanese sample is the only totally unclustered sample, with households randomly selected in each of the four sample areas and one random respondent } \\
\text { selected in each sample household. Six of the ten surveys are based on NR household samples, whereas two others are based on NR household samples in urbanised areas } \\
\text { (Colombia, Mexico). } \\
\text { b. Brazil, New Zealand and Romania did not have an age restricted part } 2 \text { sample. All other countries, with the exception of India (which was age restricted to 39), were age } \\
\text { restricted to } 44 \text { years. } \\
\text { c. The response rate is calculated as the ratio of the number of households in which an interview was completed to the number of households originally sampled, excluding from } \\
\text { the denominator households known not to be eligible either because of being vacant at the time of initial contact or because the residents were unable to speak the designated } \\
\text { languages of the survey. The weighted average response rate is } 74.4 \% \text {. } \\
\text { d. New Zealand interviewed respondents } 16+\text { but for the purposes of cross-national comparisons we limited the sample to those } 18+\text {. }\end{array}$} \\
\hline
\end{tabular}

these languages were excluded. Quality control protocols were standardised across countries to check on interviewers' reliability and specify data cleaning and coding procedures. The institutional review board of the organisation that coordinated the survey in each country approved and monitored compliance with procedures for obtaining informed consent and protecting participants.

\section{Measures}

All surveys used the World Mental Health Survey version of the WHO Composite International Diagnostic Interview (WMH-CIDI, version 3.0), a fully structured diagnostic interview composed of two parts to reduce participant burden and cost. ${ }^{9}$ Part one was for core diagnostic assessment of various mental disorders including major depressive disorder and bipolar disorders. Part two included additional information relevant to a wide range of survey objectives. All participants completed part one and those meeting criteria for any mental disorder and a probability sample of other participants were administered part two. Part two participants were weighted by the inverse of their probability of selection for part two of the interview to adjust for differential sampling. The WMH-CIDI field trials and later clinical calibration studies showed that all the disorders considered herein were assessed with acceptable reliability and validity. ${ }^{9}$ Specifically, concordance was high for bipolar disorder I (area under receiver operating characteristic curve $(\mathrm{AUC})=0.99$, Cohen's kappa $(\kappa)=0.88)$ and acceptable for bipolar disorder II $(\mathrm{AUC}=0.83, \kappa=0.50)$ and any bipolar disorder $(\mathrm{AUC}=0.93, \kappa=0.69){ }^{12}$

\section{Bipolar disorders}

According to DSM-IV criteria, participants were classified as having lifetime bipolar disorder I if they ever had a manic episode, defined as a period of 7 days or more with elevated mood plus three other mania-related symptoms, or irritable mood plus four other mania-related symptoms and the mood disturbance resulted in marked impairment, the need for hospitalisation or psychotic features. To be classified as having lifetime bipolar disorder II, a participant had a major depressive episode and a hypomanic episode, defined as a period of 4 days or more with symptom number criteria similar to mania as above and associated with unequivocal change in functioning, but without any manic episode. The DSM-IV requirement that symptoms do not meet criteria for a mixed episode (criterion C for mania/hypomania and criterion B for major depressive episode) was not operationalised in making these diagnoses. Among participants with 
lifetime bipolar disorder I or II, those reporting major depressive episode or manic/hypomanic episode at anytime in the 12 months before interview were classified as having 12-month bipolar disorder. The corresponding number of manic/hypomanic episodes and major depressive episodes were assessed. Participants with at least four mood episodes of any combination within that year were classified as having 12-month rapid-cycling bipolar disorder. Three mutually exclusive groups: the 12-month rapidcycling bipolar disorder (BPD-RC) group, the 12-month nonrapid cycling (12-month BPD-nonRC) group and the other lifetime non-rapid-cycling bipolar disorder group (lifetime BPDnonRC) were compared in this study. The 12-month BPD-RC group was compared with the 12-month BPD-nonRC group to see how the rapid cycling phenomenon manifested in this recent group of people with bipolar disorder; it was also compared with the lifetime BPD-nonRC group to see how rapid-cycling bipolar disorder differs from general bipolar disorder without rapid cycling.

For those having episodes in the past 12 months we also assessed symptom severity and role impairment. Symptom severity for the most severe month was assessed with the selfreport versions of the Young Mania Rating Scale (YMRS) for mania/hypomania ${ }^{13}$ and the Quick Inventory of Depressive Symptoms (QIDS) for major depressive episode. ${ }^{14}$ We divided severity of manic/hypomanic episode and major depressive episode into very severe (YMRS 25+; QIDS: 16+), moderate (YMRS 15-24; QIDS 11-15), mild (YMRS 9-14; QIDS 6-10) or clinically non-significant (YMRS 0-8; QIDS 0-5). Role impairment was assessed with the Sheehan Disability Scale (SDS) ${ }^{15}$ This asked participants to focus on the month when the manic/hypomanic episode or major depressive episode was most severe and rate how much the condition interfered with home management, work, social life and close relationships using a visual analogue scale. Similar to a Likert scale, the impairment was scored from 1 to 10: none (0), mild (1-3), moderate (4-6), severe (7-9), very severe (10). Clinical features such as age at onset, course, longest lifetime episode, number of months in episode during previous years were asked for both manic/ hypomanic episodes and major depressive episodes. Age at onset was assessed with retrospective self-report at syndrome level, as was course of illness by asking participants to estimate the number of years in which they had at least one episode. Annual persistence was defined as the number of years with depressive and/or manic/ hypomanic episodes divided by number of years between age at onset and age at interview.

\section{Other disorders}

Assessment of other core DSM-IV disorders included anxiety disorders (generalised anxiety disorder, panic attack, panic disorder and/or agoraphobia, post-traumatic stress disorder, obsessive-compulsive disorder, specific phobia, social phobia and separation anxiety disorder), impulse-control disorders (attention-deficit hyperactivity disorder, oppositional dysfunction disorder, conduct disorder and intermittent explosive disorder) and substance use disorders (alcohol misuse and dependence, drug misuse and dependence). Organic exclusion rules and diagnostic hierarchy rules were used in making all diagnoses. Masked clinical reappraisal interviews using the non-patient version of the Structured Clinical Interview for DSM-IV (SCID) ${ }^{16}$ with a probability subsample of participants in the US National Comorbidity Survey Replication (NCS-R) found generally good concordance of CIDI/DSM-IV diagnoses of anxiety, mood and substance use disorders with independent clinical assessments. ${ }^{17-19}$ Clinical reappraisal interviews did not include the assessment of impulse-control disorder diagnoses.

\section{Other measures}

The following types of childhood adversities were asked with dichotomous questions in part two of the WMH-CIDI: loss of parents (parental death, parental divorce, other types of loss of contact with parents), adverse parental factors (mental disorder, substance use, criminal behaviour and violence), abuse (physical, sexual and neglect) and other (participants' serious physical illness and family poverty). We also considered the association of bipolar disorder with sociodemographic variables such as gender, age at interview (18-34, 35-49, 50-64, 65+), marital status at the time of interview (married, previously married, never married), education level compared with local country standard (low, lowaverage, high-average, high), employment status (working, student, homemaker, retired, other including those unemployed) and household income compared with local country standard (low, low-average, high-average, high). Concerning suicidality, we asked all part two participants (part one participants in New Zealand survey) whether they ever in their life seriously thought about committing suicide. If this was the case we asked the age when this first happened and then whether they ever made a suicide plan, a suicidal attempt and the age of their first occurrence. Finally, all part two participants were asked about 12-month and lifetime treatment of any problem concerning emotions, nerves or substance use. These treatment questions included treatment by psychiatrist, other mental health professional (psychologist, psychotherapist and psychiatric nurse), general medical provider, human services professional and complementary-alternative medical provider (e.g. acupuncturist, chiropractor, spiritual healer), receiving treatment specific to a major depressive episode and/or mania-hypomania, hospitalisation for major depressive episode and/or mania-hypomania, and use of indicated medications.

\section{Statistical analysis}

Most analyses were based on the weighted part one sample $(n=54257)$. When some variables were only available for the part two sample (such as childhood adversities, suicidality, some sociodemographic variables like income), analyses were based on the part two subsample $(n=28988)$. Additional weights were used to adjust for differential probabilities of selection within households, adjusted for non-response and matched the samples to population sociodemographic distributions. We compared the proportions and means for prevalence, persistence, severity and treatment among three subgroups (BPD-RC, 12-month BPD-nonRC, lifetime BPD-nonRC). Using logistic regression analysis, we studied predictors (childhood adversities) and correlates (sociodemographics, comorbid disorders) based on design-corrected variance-covariance matrices. For suicidality subsequent to the onset of bipolar disorder, we estimated first onset by using discrete time survival analysis with person-year treated as the unit of analysis. Because of the complex sampling design with weighting and clusters, standard errors of the above analysis were estimated using Taylor series linearisation method implemented by the SUDAAN software system, version 8.0.1 (Research Triangle Institute, North Carolina, USA, see www.rti.org/SUDAAN/) on UNIX, Solaris/ SUN OS. The same set of analyses were done to compare between subgroups of bipolar I (BP-I-RC, 12-month BP-I-nonRC, lifetime BP-I-nonRC) and bipolar II disorder (BP-II-RC, 12-month BP-II-nonRC, lifetime BP-II-nonRC). However, these subgroup comparisons were deemed to be restricted because of small sample sizes. Statistical significance was evaluated using two-sided, 0.05 degree level. 


\section{Results}

\section{Prevalence, age at onset and other clinical characteristics}

Lifetime prevalence estimates of any bipolar disorders, bipolar I and bipolar II disorder of the total pooled sample were $1.1 \%$, $0.7 \%$ and $0.5 \%$ respectively. Most of the lifetime bipolar disorder occurred in the recent 12 months (12-month prevalence for any bipolar disorders $0.8 \%$; bipolar I disorder $0.4 \%$; bipolar II disorder $0.3 \%$ ). The 12 -month prevalence estimates of the BPD-RC, BP-I-RC and BP-II-RC groups were $0.3 \%, 0.2 \%$ and $0.1 \%$ respectively. Thus, roughly a third of participants with lifetime bipolar disorder and 4/10 of those with 12-month bipolar disorder met criteria for rapid cycling. There were cross-national variations in the lifetime prevalence estimates of any bipolar disorder $(0.0-2.1 \%)$, bipolar I $(0.0-1.0 \%)$ and bipolar II $(0.0-$ $1.1 \%$ ) disorders and the 12-month prevalence estimates of rapid-cycling bipolar $(0.0-0.7 \%)$ and non-rapid cycling bipolar disorders $(0.0-0.7 \%)$. There was zero prevalence of rapid-cycling bipolar disorder in three sites, namely, Bulgaria, Japan and Pondicherry (online Table DS1).

The BPD-RC group exhibited earlier age at onset of any mood episodes (16.7 years) than the 12-month BPD-nonRC group (19.7 years, $\left.\chi^{2}(1)=10.7, P<0.01\right)$ and the other lifetime BPD-nonRC group $\left(20.3\right.$ years, $\left.\chi^{2}(1)=12.1, \quad P<0.01\right) \quad$ (Table 2$)$. When manic/hypomanic episodes and major depressive episodes were examined separately, the BPD-RC group also showed earlier age at onset than the BPD-nonRC group (results not shown but available upon request). Compared with the 12-month BPDnonRC group, the BPD-RC group showed more lifetime mood episodes (103.2 v. 30.9), more mood episodes in the year before interview (13 v. 1.5), a more extended longest lifetime episode (160.8 v. 93.9 weeks), more years in lifetime with any mood episode (14.8 v. 7.7 years), higher percentage of years after first onset of mood episode to have at least one episode $(70 \% \mathrm{v}$. $60 \%)$ and more weeks with episode in the previous year $(32.5 \mathrm{v}$. 14.8 weeks). These findings on more and longer episodes were similar when the BPD-RC group was compared with the other lifetime BPD-nonRC group (Table 2).

\section{Lifetime comorbidity and 12-month suicidality}

The BPD-RC group demonstrated even more comorbidity with lifetime anxiety disorders (odds ratio $(\mathrm{OR})=25.2, v$. BPD-nonRC group, Wald $\chi^{2}=7.3, P<0.01 ; v$. other lifetime BPD-nonRC group, Wald $\left.\chi^{2}=16.2, P<0.01\right)$ than the 12-month BPD-nonRC group $(\mathrm{OR}=8.7)$ and the other lifetime BPD-nonRC group $(\mathrm{OR}=5.5)$. This difference in comorbidity was more obvious for generalised anxiety disorder, specific phobia and social phobia than other anxiety disorders, but it was still significant for panic disorder when compared with other lifetime BPD-nonRC groups (Table 3 ). Whereas the differences in odds ratios were not significant in the comparisons between the BPD-RC and the 12-month BPD-nonRC groups for other mental disorders, the BPD-RC group showed stronger comorbidity, relative to other lifetime BPD-nonRC group, with any substance use disorders as a group $\left(\mathrm{OR}=6.9 v .4 .1\right.$, Wald $\left.\chi^{2}=4.1, P=0.04\right)$, attention-deficit hyperactivity disorder $\left(\mathrm{OR}=11.0\right.$ v. 4.8 , Wald $\left.\chi^{2}=4.4, P=0.04\right)$ and oppositional defiant disorder $\left(\mathrm{OR}=8.7\right.$ v. 2.9 , Wald $\chi^{2}=10.0$, $P<0.01)$. For suicidality, although the BPD-RC, 12-month $\mathrm{BPD}$-nonRC and other lifetime BPD-non RC groups all showed elevated odds ratio on predicting first onset of suicide ideation $(\mathrm{ORs}=2.1-3.1)$, plan $(\mathrm{ORs}=1.7-5.0)$ and attempt $(\mathrm{ORs}=2.2-$ 4.8 ) in previous years, the BPD-RC group did not show

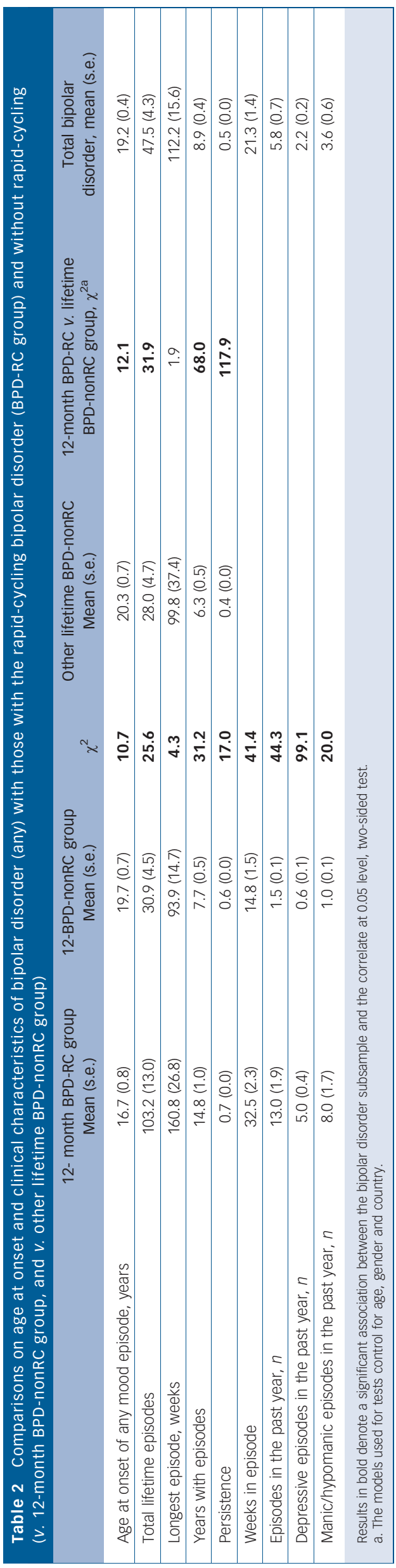




\begin{tabular}{|c|c|c|c|c|c|c|}
\hline Comorbidity & Sample $(n)$ & $\begin{array}{c}\text { 12-month BPD-RC } \\
\text { group } \\
\text { OR }(95 \% \mathrm{Cl})\end{array}$ & $\begin{array}{l}\text { 12-month } \\
\text { BPD-nonRC group } \\
\text { OR }(95 \% \mathrm{Cl})\end{array}$ & $\chi^{2 b}$ & $\begin{array}{c}\text { Other lifetime } \\
\text { BPD-nonRC group OR } \\
(95 \% \mathrm{Cl})\end{array}$ & $\begin{array}{l}\text { 12-month BPD-RC } \\
\text { group } v \text {. lifetime } \\
\text { BPD-nonRC group, } \chi^{2 b}\end{array}$ \\
\hline Any anxiety disorders & Part 2 (28988) & $25.2(12.0-53.0)$ & $8.7(5.7-13.3)$ & 7.3 & $5.5(3.4-8.9)$ & 16.2 \\
\hline Generalised anxiety disorder & Part 1 (54 257) & $13.8(9.0-21.3)$ & $7.6(5.0-11.5)$ & 5.2 & $5.7(3.6-9.0)$ & 11.0 \\
\hline Agoraphobia & Part 1 (54 257) & $10.2(5.1-20.5)$ & $7.1(3.7-13.4)$ & 0.8 & $5.7(3.1-10.6)$ & 1.9 \\
\hline Specific phobia & Part 1 (54 257) & $11.5(7.6-17.5)$ & $6.6(4.5-9.7)$ & 4.9 & $2.9(2.0-4.3)$ & 29.8 \\
\hline Social phobiac & Part 1 (54 257) & $13.6(8.7-21.2)$ & $7.0(4.8-10.4)$ & 5.9 & $6.1(4.1-9.1)$ & 8.5 \\
\hline Post-traumatic stress disorder & Part 2 (28988) & $6.9(4.5-10.5)$ & $6.7(4.5-9.9)$ & 0.0 & $4.1(2.6-6.6)$ & 4.4 \\
\hline Obsessive-compulsive disorder & $\begin{array}{l}\text { Randomly selected } \\
\text { Part } 2 \text { (17 454) }\end{array}$ & $7.4(2.9-19.3)$ & $7.5(3.3-16.9)$ & 0.0 & $3.5(1.5-8.1)$ & 2.2 \\
\hline Panic disorder & Part 1 (54 257) & $10.9(6.3-18.8)$ & $7.7(4.5-13.1)$ & 1.2 & $3.2(1.7-6.0)$ & 10.6 \\
\hline Panic attack & Part 1 (54 257) & $10.3(6.0-17.7)$ & $7.0(4.7-10.3)$ & 1.7 & $4.4(2.9-6.6)$ & 9.2 \\
\hline Separation anxiety ${ }^{c, d}$ & Part 2 (28988) & $9.9(5.8-16.9)$ & $8.3(4.9-14.1)$ & 0.2 & $4.8(2.7-8.6)$ & 4.3 \\
\hline Any substance use disorders & Part 2 (28988) & $6.9(4.5-10.7)$ & $5.2(3.5-7.6)$ & 1.3 & $4.1(2.7-6.4)$ & 4.1 \\
\hline Alcohol misuse & Part 2 (28988) & $6.5(4.2-10.3)$ & $4.9(3.3-7.4)$ & 1.2 & $4.3(2.7-6.9)$ & 2.2 \\
\hline Alcohol dependence & Part 1 (54 257) & $6.8(4.0-11.7)$ & 5.7 (3.5-9.3) & 0.4 & $5.4(3.1-9.6)$ & 0.5 \\
\hline Drug misuse & Part 2 (28988) & $4.6(2.8-7.4)$ & $4.4(2.9-6.8)$ & 0.0 & $2.7(1.7-4.4)$ & 3.3 \\
\hline Drug dependence ${ }^{\mathrm{e}}$ & Part 1 (54 257) & $5.1(2.5-10.2)$ & $5.0(2.6-10.0)$ & 0.0 & $2.8(1.4-5.7)$ & 2.8 \\
\hline Any impulse-related disorder & $\begin{array}{l}\text { Part } 2 \text { and age } \\
\leqslant 44(12014)\end{array}$ & $8.5(4.8-15.2)$ & $8.0(4.6-13.9)$ & 0.0 & $6.0(2.9-12.2)$ & 1.0 \\
\hline Attention-deficit hyperactivity disorder & $\begin{array}{l}\text { Part } 2 \text { and age } \leqslant 44 \\
\text { (12014) }\end{array}$ & $11.0(5.9-20.5)$ & $9.1(5.0-16.7)$ & 0.3 & $4.8(2.1-11.2)$ & 4.4 \\
\hline Oppositional dysfunction disorder ${ }^{\mathrm{C}}$ & $\begin{array}{l}\text { Part } 2 \text { and age } \leqslant 44 \\
(12014)\end{array}$ & $8.7(4.5-16.7)$ & $6.6(3.0-14.4)$ & 0.8 & $2.9(1.3-6.6)$ & 10.0 \\
\hline Conduct disorder & $\begin{array}{l}\text { Part } 2 \text { and age } \leqslant 44 \\
\text { (12014) }\end{array}$ & $5.5(2.8-10.7)$ & $4.3(1.9-9.5)$ & 0.4 & $2.5(1.0-5.9)$ & 3.3 \\
\hline Intermittent explosive disorder ${ }^{\mathrm{c}, \mathrm{f}}$ & Part 1 (54257) & $4.2(2.2-8.0)$ & $3.2(1.9-5.6)$ & 0.6 & $2.8(1.3-6.0)$ & 0.8 \\
\hline Any disorder & Part 2 (28988) & $37.1(12.5-110.0)$ & $10.5(6.5-17.0)$ & 5.0 & $6.0(3.4-10.4)$ & 11.1 \\
\hline Exactly 1 disorder & Part 2 (28988) & $8.7(2.5-30.6)$ & $4.6(2.1-10.0)$ & 1.0 & $2.9(1.4-6.0)$ & 3.0 \\
\hline Exactly 2 disorders & Part 2 (28 988) & & $3.6(1.4-9.1)$ & 1.3 & $2.1(0.9-5.0)$ & 0.1 \\
\hline 3 or more disorders & Part 2 (28988) & 107.7 (33.2-349.3) & $24.6(14.9-40.8)$ & 6.1 & $13.6(7.4-25.0)$ & 12.0 \\
\hline \multicolumn{7}{|c|}{$\begin{array}{l}\text { Results in bold denote significant difference between the bipolar subsample at the } 0.05 \text { level, two-sided test. } \\
\text { a. Odds ratios (ORs) are based on models predicting lifetime disorders by bipolar disorders and controlling for age, gender and country. } \\
\text { b. } \chi^{2} \text { : the models used to generate the results in this table included three dummy predictor variables for the different types of bipolar disorder to predict each of the other } \\
\text { disorders controlling for age and gender. Significance tests of pair-wise differences in the ORs of rapid cycling with either other } 12 \text {-month bipolar disorder or other lifetime bipolar } \\
\text { disorder were based on wald } \chi^{2} \text { estimated in these models. The exception was the model for number of comorbid disorders (exactly one, exactly two, three or more), in which } \\
\text { three separate subsample analyses were used to predict exactly one } v \text {. none, exactly two } v \text {. none, and three or more } v \text {. none. Sample sizes differed because although most } \\
\text { comorbid disorders were assessed in part one, others (post-traumatic stress disorder, drug misuse and dependence) were assessed in part two, and yet others (attention-deficit } \\
\text { hyperactivity disorder, oppositional dysfunction disorder, conduct disorder) in the subsample of the part two sample in the age range 18-44. Obsessive-compulsive disorder, finally, } \\
\text { was assessed in the random subsample of part two respondents. } \\
\text { c. For social phobia, separation anxiety, oppositional dysfunction disorder and intermittent explosive disorder, USA/non-USA was used as control instead of country. } \\
\text { d. For separation anxiety, gender was removed as a control. } \\
\text { e. For drug dependence, age group } 50-64 \text { was removed as a control. } \\
\text { f. For intermittent explosive disorder, USA, Japan and New Zealand were used as controls instead of country. }\end{array}$} \\
\hline
\end{tabular}

significantly higher likelihood than the other two groups (further details available upon request).

\section{Symptom severity and role impairment}

Although most participants in the BPD-RC group reported severe manic/hypomanic symptoms (63.2\%), the proportion was not significantly higher than that of the BPD-nonRC group $(54.1 \%$, Wald $\left.\chi^{2}=0.1, P=0.798\right)$. The proportion of those reporting severe depressive symptoms was also not significantly higher among the BPD-RC $(80.3 \%)$ than the BPD-nonRC group $(72.3 \%$, Wald $\left.\chi^{2}=3.1, P=0.077\right)$.

A higher proportion of participants in the BPD-RC than the BPD-nonRC group $\left(86.9 \%\right.$ v. $66.6 \%$, Wald $\left.\chi^{2}=3.9, P=0.05\right)$ showed severe role impairment from depressive episodes, but not manic/hypomanic episodes $\left(66.3 \%\right.$ v. $56.6 \%$, Wald $\chi^{2}=12$, $P=0.28)$. Participants in the BPD-RC group also reported more days out of role owing to mania/hypomania (50.5 v. 20.6 days, Wald $\left.\chi^{2}=4.2, P=0.04\right)$ and depression (81.6 v. 63.9 days, Wald $\chi^{2}=0.1, P=0.79$ ), although the difference for the latter was not significant (detailed results available upon request).

\section{Family and childhood predictors and sociodemographic correlates}

Parental depression was associated with elevated odds of bipolar disorder $(\mathrm{ORs}=1.9-11.7)$, as were panic $(\mathrm{ORs}=3.2-6.5)$, generalised anxiety (ORs $=3.5-12.3)$, substance use $(\mathrm{ORs}=2.8-4.1)$ and antisocial personality $(\mathrm{ORs}=2.2-2.6)$ disorders (Table 4$)$. The difference between those with and without rapid cycling varied across the bipolar I and bipolar II disorder groups. The elevated risks were commonly larger for those with bipolar I disorder, with those in the BP-I-RC group showing even higher risks (ORs = 2.79.3) than those in other lifetime BP-I-nonRC group on parental psychopathology. For those with bipolar II disorder, the difference between the BP-II-RC group and other bipolar II disorder groups was not significant (detailed results for bipolar I and bipolar II disorders are available upon request).

For other childhood adversity predictors, the pattern of elevations was similar between the bipolar I and bipolar II disorder groups (Table 4). The overall results showed that neglect (ORs $=1.4-4.0)$, physical abuse (ORs $=2.6-6.9)$, sexual abuse (ORs $=4.3-5.6)$, other types of loss of contact with parents (ORs $=2.2-3.5)$, and parental violence and criminal behaviour $(\mathrm{ORs}=2.9-3.5)$ were associated with bipolar disorder. Besides 


\begin{tabular}{|c|c|c|c|c|c|}
\hline & $\begin{array}{l}\text { 12-month BPD-RC } \\
\text { group, OR }(95 \% \mathrm{Cl})\end{array}$ & $\begin{array}{l}\text { 12-month BPD-nonRC } \\
\text { group, OR }(95 \% \mathrm{CI})\end{array}$ & $\chi^{2}$ & $\begin{array}{l}\text { Other lifetime } \\
\text { BPD-nonRC group } \\
\text { OR }(95 \% \mathrm{Cl})\end{array}$ & $\begin{array}{l}\text { 12-month BPD-RC } \\
\text { group v. lifetime } \\
\text { BPD-nonRC group, } \chi^{2}\end{array}$ \\
\hline \multicolumn{6}{|l|}{ Parents' mental disorder } \\
\hline Depression & $2.6(0.8-8.0)$ & $11.7(6.0-22.5)$ & 4.0 & $1.9(0.5-6.8)$ & 0.5 \\
\hline Panic & $3.3(1.7-6.7)$ & $6.5(3.5-12.0)$ & 1.6 & $3.2(1.5-6.6)$ & 0.2 \\
\hline Generalised anxiety & $3.5(1.5-8.2)$ & $12.3(6.6-23.0)$ & 3.3 & $3.9(1.4-10.5)$ & 0.1 \\
\hline Substance use problem & $2.9(1.3-6.4)$ & $2.8(1.5-5.2)$ & 0.1 & $4.1(2.4-7.0)$ & 0.4 \\
\hline Antisocial personality & $2.2(0.9-5.8)$ & $2.6(1.1-6.1)$ & 0.0 & $2.3(0.9-5.5)$ & 0.0 \\
\hline Neglect and abuse & $4.1(2.4-6.9)$ & $5.0(3.1-8.1)$ & 0.3 & $2.1(1.2-3.7)$ & 2.8 \\
\hline Neglect & $4.0(2.0-7.8)$ & $1.6(0.8-3.3)$ & 3.9 & $1.4(0.6-3.2)$ & 4.0 \\
\hline Physical abuse & $4.0(2.3-6.9)$ & $6.9(4.2-11.1)$ & 3.6 & $2.6(1.4-4.7)$ & 1.5 \\
\hline Sexual abuse & $5.0(2.8-9.1)$ & $5.6(3.2-10.0)$ & 0.2 & $4.3(2.2-8.6)$ & 0.1 \\
\hline Loss of parents & $1.8(1.1-3.1)$ & $0.9(0.5-1.4)$ & 5.1 & $0.9(0.5-1.4)$ & 4.3 \\
\hline Death & $1.2(0.6-2.6)$ & $0.8(0.4-1.4)$ & 0.4 & $0.5(0.3-0.8)$ & 2.3 \\
\hline Divorce & $1.8(0.9-3.5)$ & $0.7(0.4-1.4)$ & 5.0 & $0.9(0.4-1.9)$ & 2.8 \\
\hline Other major loss & $3.5(1.7-7.2)$ & $2.3(1.2-4.3)$ & 1.0 & $2.2(1.0-4.7)$ & 1.2 \\
\hline Parents' violence and criminality & $3.0(1.7-5.4)$ & $3.5(2.2-5.5)$ & 0.0 & $2.9(1.7-5.0)$ & 0.1 \\
\hline Violence & $3.6(1.9-6.6)$ & $3.3(2.2-5.1)$ & 0.2 & $2.9(1.6-5.3)$ & 0.4 \\
\hline Criminal behaviour & $2.2(1.0-4.7)$ & $3.3(1.6-7.1)$ & 0.2 & $4.6(2.3-9.1)$ & 1.4 \\
\hline Other family adversity & $2.2(1.3-3.7)$ & $4.1(2.5-6.6)$ & 1.5 & $2.5(1.5-4.1)$ & 0.0 \\
\hline Economic adversities & $2.3(1.1-4.6)$ & $2.3(1.2-4.3)$ & 1.0 & $0.8(0.3-2.7)$ & 3.4 \\
\hline Respondent's severe physical illness & $3.6(1.6-7.9)$ & $1.5(0.5-4.3)$ & 2.2 & $1.6(0.6-4.3)$ & 1.8 \\
\hline Any childhood adversities & $3.4(2.0-5.8)$ & $2.8(1.7-4.6)$ & 0.7 & $2.4(1.5-3.9)$ & 1.1 \\
\hline
\end{tabular}

the findings that neglect and loss of parents in general were more elevated for those in the BPD-RC than in the BPD-nonRC group, there was no elevation for the BPD-RC group with other childhood adversities.

Examination of sociodemographic correlates including gender, marital status, education level, employment status and household income showed that younger age, lower education and other employment status (including being unemployed) were associated with bipolar disorder. However, gender was not associated with rapid-cycling bipolar disorder (Wald $\chi^{2}=0.7, \quad P=0.402$ ). Concerning the difference between the BPD-RC and BPD-nonRC groups, we only found a difference for marital status (Wald $\left.\chi^{2}=9.6, P=0.01\right)$ in that rapid-cycling bipolar disorder was associated more with those previously married $(\mathrm{OR}=1.9$, Wald $\left.\chi^{2}=6.0, P=0.05\right)$, but such an elevation did not exist for non-rapid-cycling bipolar disorder.

\section{Treatment}

More participants in the BPD-RC than the other BPD-nonRC group received lifetime mental health service not provided by psychiatrists (12-month BPD-RC $47.7 \% v$. other lifetime BPDnonRC group $32.8 \%$, Wald $\left.\chi^{2}=5.8, P=0.016\right)$ and lifetime general medical services $\left(54.3 \% \quad\right.$ v. $43.2 \%$, Wald $\chi^{2}=3.9$, $P=0.049$ ). More of them also received lifetime treatment of major depressive episodes $\left(67.1 \%\right.$ v. $51.6 \%$, Wald $\left.\chi^{2}=4.5, P=0.033\right)$ but not mania/hypomania. These patterns were more prominent in the BP-I-RC than the BP-II-RC subgroups. A significantly larger portion of those in the BPD-RC group were prescribed some form of medication $(55.3 \%)$ compared with those in the 12-month BPD-nonRC (30.3\%) and other lifetime BPD-nonRC (32\%) groups. Among those seeing psychiatrists, there was no significant difference between those with rapid-cycling bipolar disorder $(52.8 \%)$ and those with other bipolar disorders $(35.9 \%$ for the 12-month BPD-nonRC group, $31.6 \%$ for the lifetime BPD-nonRC group) on being prescribed mood stabilising or antipsychotic medications (details of separate distributions on treatment and medications for bipolar I and bipolar II disorders are available upon request).

\section{Discussion}

\section{Methodological considerations}

Interpretations of our findings must take account of the following issues. One fundamental issue is about the definition of rapidcycling bipolar disorder. Clinical studies that adopted different definitions for rapid-cycling bipolar disorder captured different, although overlapping, patient groups. ${ }^{3}$ Our finding of rapidcycling bipolar disorder showing substantially more lifetime (103.2 v. 30.9) and 12-month (13 v. 1.5) mood episodes than non-rapid-cycling bipolar disorder suggested that the WHM-CIDI did not capture rapid-cycling bipolar disorder in the same way as clinicians diagnose using the DSM-IV. The DSM-IV requires 2 months of full or partial remission or switching of polarity in the counting of the offset of a mood episode. Partial remission is not defined and its determination during clinical interviews may be arbitrary. The WMH-CIDI did not directly assess time between episodes, although the offset of a major depressive episode was established by a respondent reporting 'no longer have the problems for 2 weeks in a row'. The offset of a manic/ hypomanic episode was not specifically defined. At this stage, there are no data to show whether a clinician's judgement of 2 months of full or partial remission of a depressive episode is more or less stringent than a respondent's self-report of 2 full weeks of wellness. Whereas 2 months of clinically assessed full or partial remission seem more stringent than the 2-week WMH-CIDI requirement, participants who were in partial 
remission for 2 months might continue to feel unwell and thus not endorse the CIDI remission question. This is because clinically judged remission (especially partial remission) might nonetheless be associated with significant subsyndromal self-reported mood, cognitive and functional disturbances among individuals with bipolar disorder. ${ }^{8,20,21}$ Consequently, some participants might experience several clinical mood episodes as a longer continuous episode and reported them as such. This possibility was supported by prospective studies using daily mood ratings that showed that brief mood episodes were as frequent as full-duration DSM-IVdefined episodes. ${ }^{5}$ Since clinicians typically followed the DSM-IV categorical cut-off of four or more episodes and there is at present little difference in treatment given to people with different degrees of rapid cycling, they may not be inclined to count the exact number of milder episodes for the purpose of subtyping bipolar disorder as rapid cycling.

The WMH-CIDI cannot establish episode offset by using switching of polarity in a way that a clinician's interview can. Furthermore, it is by no means straightforward to examine 'ultra-rapid' and 'ultradian cycling' bipolar disorder or 'truncated-episode' rapid cycling (four or more episodes that last at least 1 day at full severity) in a community survey that employs lay interviewers. ${ }^{3}$ To date, no community epidemiological interview instrument administered by lay interviewers has been clinically validated with reference to rapid-cycling bipolar disorder. Since the cardinal feature of rapid-cycling bipolar disorder is multiple annual episodes, rapid-cycling bipolar disorder generated by the WMH-CIDI provides a fair epidemiological proxy for a bipolar phenotype defined as DSM-IV rapid-cycling bipolar disorder. ${ }^{10}$

Another limitation is that mixed episode was not assessed because, when defined according to the DSM-IV requirement for full mania/hypomania and full major depressive episode coexisting, ${ }^{10}$ it is hard to operationalise in the WMH-CIDI. This omission could lead to double counting of mood episodes and thus overestimation of the number of mood episodes because DSM-IV mixed episodes should not be counted as manic/ hypomanic or/and depressive episodes. Nonetheless, researchers have found that mixed episode as defined by the DSM-IV was rigid and rare. ${ }^{6,22,23}$ This would suggest that any overestimation might be small. Retrospective recall could lead to bias in findings on persistence and clinical severity. No data are available on the accuracy of these reports. Besides, clinical severity was evaluated with reference to the most severe month in the previous 12 months. This single-month approach might minimise differences that could exist in the severity of participants' illness across the subsamples.

\section{Community $v$. clinical findings}

Using an identical methodology across the sites of study we showed that rapid-cycling bipolar disorder is a relatively rare condition in the community. There was cross-national variation in prevalence of both bipolar disorder and rapid-cycling bipolar disorder. The overall 12-month prevalence estimates of bipolar disorder $(0.8 \%)$ and rapid-cycling bipolar disorder $(0.3 \%)$ we found were lower than those found in the NCS-R study $(1.4 \%$ and $0.7 \%){ }^{24}$ This discrepancy is consistent with the repeated finding of higher prevalence of mood disorders in the USA than other WMH countries. It may reflect a genuinely higher level of bipolar disorder in the USA than non-US countries. ${ }^{25}$ Potential aetiological factors that vary across countries such as the prevalence of depression, frequency of antidepressant prescription, childhood adversity and thyroid dysfunction may contribute to this. ${ }^{26-28}$

We confirmed the results of other well-documented clinical findings about rapid-cycling bipolar disorder and that it is common among those with bipolar disorder in the community. About a third of participants with lifetime bipolar disorder and $4 / 10$ of those with 12-month bipolar disorder met criteria for 12-month rapid-cycling bipolar disorder. These proportions were higher than the prevalence of rapid cycling found among cases of bipolar disorder in major clinical studies such as the Collaborative Depression Study (CDS: $25.8 \%)^{29}$ and the EMBLEM study (17.3\%; range of 2.2 to $23.0 \%$ across European countries). ${ }^{27}$ They were, however, comparable to those found in the NCS- ${ }^{24}$ and the Stanley Bipolar Network study (38.2\%), which included ultra-rapid and ultradian-cycling bipolar disorder in the estimation of prevalence. ${ }^{5}$ Apart from methodological differences, the higher frequency we found could reflect the fact that rapidcycling bipolar disorder identified in a community setting consisted of a wider spectrum of severity and other characteristics that might determine whether affected individuals would seek help from specialised mood centres. Nonetheless, the finding that $83.4 \%$ of those with rapid-cycling bipolar disorder had received lifetime treatment suggested that the illness was very impairing. Since psychiatrists were not most commonly involved in such treatment, rapid-cycling bipolar disorder in the community was not a primarily drug-induced condition as suggested in some clinical studies. ${ }^{27}$ Previous studies were inconsistent with regard to whether rapid cycling was more ${ }^{5}$ or less $^{28}$ common in bipolar I than bipolar II disorder. We did not find any difference.

Rapid-cycling bipolar disorder compared with non-rapidcycling bipolar disorder exhibited several distinguishing characteristics indicating that it is a more severe form of bipolar disorder. ${ }^{3,26,30}$ One is the greater frequency and persistence of episodes (Table 2). This confirmed prospective clinical studies indicating that the proportion of days depressed in the preceding year was significantly associated with shorter time to depressive recurrence. ${ }^{31}$ Other non-episode severity indicators of rapidcycling bipolar disorder we found included higher comorbidity with other mental (especially anxiety) disorders, ${ }^{5,30,32}$ higher SDS impairment due to major depressive episodes and more days out of role due to mania/hypomania. That the overall severity of clinical symptoms and role impairment was greater with depression than mania/hypomania was consistent with other clinical studies. ${ }^{20,29,33,34}$ The greater severity of rapid-cycling bipolar disorder was also shown by the higher frequency of receiving lifetime health services ${ }^{35}$ and its greater association with previously married status. One finding that was inconsistent with some previous studies of rapid-cycling bipolar disorder was about suicidality. ${ }^{26,27,29}$ Participants with 12-month rapid-cycling bipolar disorder did not exhibit significantly elevated risk of suicidality subsequent to the first onset of their disorder than participants with 12-month non-rapid-cycling bipolar disorder. This could reflect the lower severity of rapid-cycling bipolar disorder in community than those found in clinical studies. Our finding that more than half of participants with rapid-cycling bipolar disorder received 12-month health services not provided by psychiatrists would suggest that participants with rapid-cycling bipolar disorder in the community had less severe problems than those who attended specialised mood centres.

Regarding age at onset and sociodemographic profile, we confirmed the relatively consistent clinical finding that rapidcycling bipolar disorder had younger age at onset no matter whether this was assessed with reference to mania/hypomania or major depressive episodes. ${ }^{26,29}$ That depressive episodes demonstrated an earlier age at onset than manic/hypomanic episodes in both rapid-cycling and non-rapid-cycling bipolar disorder is congruous with both historical and recent studies. ${ }^{30,36,37}$ This convergence of community and clinical findings points to early age at onset as a risk factor for lifetime rapid-cycling bipolar 
disorder. By contrast, although most clinical studies indicated a female dominance in rapid-cycling bipolar disorder, ${ }^{27,30}$ we found that 12-month rapid-cycling bipolar disorder was not connected with gender. Psychosocial factors such as greater concerns about psychiatric stigma associated with help-seeking among males ${ }^{38}$ and a greater tendency for females to translate distress into conscious recognition of an emotional illness ${ }^{39}$ might both explain this discrepancy. It is worth noting that at least two studies also did not find rapid-cycling bipolar disorder to be associated with gender. ${ }^{40,41}$ Recent meta-analytic studies have concluded that the preponderance of females among people with BPD-RC was less marked than often suggested. ${ }^{28}$

We examined a much wider range of childhood adversities and parental mental disorders than in previous clinical studies. ${ }^{42}$ The significant associations for childhood adversities found for both bipolar I and II disorders were expected. ${ }^{5,43}$ Although we found that both rapid-cycling and non-rapid-cycling bipolar disorder were associated with neglect and abuse, rapid-cycling bipolar disorder was more elevated than non-rapid-cycling bipolar disorder with childhood neglect and the difference was not significant for abuse. Our findings were more specific than previous studies in suggesting that although childhood abuse was associated with bipolar disorders, deprivational stress via neglect showed consistent association for rapid-cycling but not non-rapid-cycling bipolar disorder. ${ }^{44}$ We are not aware of previous studies investigating the association of a range of parental mental disorders in childhood and bipolar disorder with and without rapid cycling in adults. That parental depression was less associated with rapid-cycling bipolar disorder than 12-month non-rapid-cycling bipolar disorder might indirectly support previous negative findings in genetic and family studies of people with rapid-cycling $v$. non- rapid-cycling bipolar disorder. ${ }^{3}$ How different developmental adversities, their timing, quantity, repetitiveness and interactions with genetic factors and current stressors may mediate the onset and course of bipolar disorder remains to be elucidated in prospective studies.

\section{Future research}

One major obstacle to the community epidemiological study of rapid-cycling bipolar disorder is accurate assessment. There is a strong need to develop a refined fully-structured instrument that can validly assess such core characteristics as the onset and offset of episodes, partial $v$. complete remission, inter-episodic intervals and mixed episodes. Dimensional measures of these characteristics are desirable for resolving uncertainty about the optimal boundary distinctions for rapid-cycling bipolar disorder as rapid cycling may be a dimensional course specifier. ${ }^{5}$ The DSM-IV definition of rapid-cycling bipolar disorder by no means captures the spectrum of rapid cycling and mixed episodes, and their definitions may change as new research evidence and experts' consensus emerge. ${ }^{6}$ When such a structured instrument is available, the validity of bipolar disorder subtypes beyond those defined in the DSM-IV and ICD $-10^{45}$ can then be examined critically from a longitudinal epidemiological perspective.

\section{Funding}

These surveys were carried out in conjunction with the World Health Organization (WHO) World Mental Health (WMH) Survey Initiative. These activities were supported by the United States National Institute of Mental Health (R01MH070884), the John D. and Catherine T. MacArthur Foundation, the Pfizer Foundation, the US Public Health Service (R13MH066849, R01-MH069864, and R01 DA016558), the Fogarty International Center (FIRCA R03-TW006481), the Pan American Health Organization (PAHO), the Eli Lilly \& Company Foundation, GlaxoSmithKline, Bristol-Myers Squibb and Shire. Additional support for preparation of this paper was provided by Ortho-MCNeil Janssen Scientific Affairs, LLC. The São Paulo Megacity Mental Health Survey is supported by the State of São Paulo Research Foundation (FAPESP) Thematic Project Grant 03/00204-3. The Bulgarian
Epidemiological Study of common mental disorders EPIBUL is supported by the Ministry of Health and the National Center for Public Health Protection. The Colombian National Study of Mental Health (NSMH) is supported by the Ministry of Social Protection. The WMHI was funded by WHO (India) and helped by Dr R Chandrasekaran, JIPMER. The World Mental Health Japan (WMHJ) Survey is supported by the Grant for Research on Psychiatric and Neurological Diseases and Mental Health (H13-SHOGAl-023, H14-TOKUBETSU-026, H16-KOKORO-013) from the Japan Ministry of Health, Labour and Welfare. The Lebanese National Mental Health Survey (LEBANON) is supported by the Lebanese Ministry of Public Health, the WHO (Lebanon), Fogarty International, Act for Lebanon, anonymous private donations to IDRAAC, Lebanon, and unrestricted grants from Janssen Cilag, Eli Lilly, GlaxoSmithKline, Roche, and Novartis. The Mexican National Comorbidity Survey (MNCS) is supported by The National Institute of Psychiatry Ramon de la Fuente (INPRFMDIES 4280) and by the National Council on Science and Technology (CONACyT-G30544- H), with supplemental support from the PAHO. Te Rau Hinengaro: The New Zealand Mental Health Survey (NZMHS) is supported by the New Zealand Ministry of Health, Alcohol Advisory Council, and the Health Research Council. The Romania WMH study projects 'Policies in Mental Health Area' and 'National Study regarding Mental Health and Services Use' were carried out by National School of Public Health \& Health Services Management (former National Institute for Research \& Development in Health), with technical support of Metro Media Transilvania, the National Institute of Statistics-National Centre for Training in Statistics, SC. Cheyenne Services SRL, Statistics Netherlands and were funded by Ministry of Public Health (former Ministry of Health) with supplemental support of Eli Lilly Romania SRL. The US National Comorbidity Survey Replication (NCS-R) is supported by the National Institute of Mental Health (NIMH; U01-MH60220) with supplemental support from the National Institute of Drug Abuse (NIDA), the Substance Abuse and Mental Health Services Administration (SAMHSA), the Robert Wood Johnson Foundation (RWJF; Grant 044708), and the John W. Alden Trust.

Sing Lee, MBBS, FRCPsych, Department of Psychiatry; Adley Tsang, BSoSC, Hong Kong Mood Disorders Center, The Chinese University of Hong Kong, Hong Kong; Ronald C. Kessler, PhD, Department of Health Care Policy, Robert Jin, MA,

Nancy Sampson, BA, Department of Health Care Policy, Harvard Medical School, Massachusetts, USA; Laura Andrade, MD, PhD, Section of Psychiatric EpidemiologyLIM 23 Department, and Institute of Psychiatry School of Medicine University of São Paulo, Brazil; Elie G. Karam, MD, St George Hospital University Medical Center Balamand University, Faculty of Medicine, Institute for Development, Research, Advocacy \& Applied Care (IDRAAC), Medical Institute for Neuropsychological Disorders (MIND), Beirut, Lebanon; Maria Elena Medina Mora, PhD, National Institute of Psychiatry, Mexico City, Mexico; Kathleen Merikangas, PhD, Mood and Anxiety Disorders Programs, Division of Intramural Research Programs, National Institute of Mental Health, Bethesda, USA; Yoshibumi Nakane, MD, Division of Human Sociology, Nagasaki International University Graduate School Nagasaki, Japan; Daniela Georgeta Popovici, MD, MSc, Senior Family Medicine, National School of Public Health and Health Services Management, Romania; Jose Posada-Villa, MD, Colegio Mayor de Cundinamarca University, Bogota, Colombia; Rajesh Sagar, MD, Department of Psychiatry, All India Institute of Medical Sciences, Delhi, India;

Department of Psychiatry, All India Institute of Medical Sciences, Delhi, India;
J. Elisabeth Wells, PhD, Department of Public Health and General Practice,

Christchurch School of Medicine and Health Science, New Zealand; Zahari Zarkov $\mathrm{PhD}$, National Centre of Public Health Protection, Sofia, Bulgaria; Maria Petukhova PhD, Department of Health Care Policy, Harvard Medical School, USA.

Correspondence: Sing Lee, Director, Hong Kong Mood Disorders Center, 7A, Block E, Staff Quarters, Prince of Wales Hospital, Shatin, NT, Hong Kong. Email: singlee@cuhk.edu.hk

First received 30 Apr 2009, final revision 13 Oct 2009, accepted 11 Nov 2009

\section{Acknowledgements}

We thank the WMH staff for assistance with instrumentation, fieldwork and data analysis. A complete list of WMH publications can be found at www.hcp.med.harvard.edu/wmh/.

\section{References}

1 Dunner DL, Fieve RR. Clinical factors in lithium carbonate prophylaxis failure. Arch Gen Psychiatry 1974; 30: 229-33.

2 Bauer MS, Calabrese J, Dunner DL, Post R, Whybrow PC, Gyulai L, et al. Multisite data reanalysis of the validity of rapid cycling as a course modifier for bipolar disorder in DSM-IV. Am J Psychiatry 1994; 151: 506-15.

3 Bauer M, Beaulieu S, Dunner DL, Lafer B, Kupka R. Rapid cycling bipolar disorder-diagnostic concepts. Bipolar Disord 2008; 10: 153-62.

4 Mackin P, Young AH. Rapid cycling bipolar disorder: historical overview and focus on emerging treatments. Bipolar Disord 2004; 6: 523-9.

5 Kupka RW, Luckenbaugh DA, Post RM, Suppes T, Altshuler LL, Keck Jr PE, et al. Comparison of rapid-cycling and non-rapid-cycling bipolar disorder based on prospective mood ratings in 539 outpatients. Am J Psychiatry 2005; 162: $1273-80$

6 Ghaemi SN. All mixed up: on the absence of diagnostic guidelines for mixed states in the ISBD Diagnostic Guidelines Task Force Report. Bipolar Disord 2008; 10: 129-30.

7 Fisfalen ME, Schulze TG, DePaulo Jr JR, DeGroot L, Badner JA, McMahon FJ. Familial variation in episode frequency in bipolar affective disorder. Am J Psychiatry 2005; 162: 1266-72. 
8 Schneck CD, Miklowitz DJ, Miyahara S, Araga M, Wisniewski S, Gyulai L, et al. The prospective course of rapid-cycling bipolar disorder: findings from the STEP-BD. Am J Psychiatry 2008; 165: 370-7.

9 Kessler RC, Ustun TB. The World Mental Health (WMH) Survey Initiative Version of the World Health rganization (WHO) Composite International Diagnostic Interview (CIDI). Int J Methods Psychiatr Res 2004; 13: 93-121.

10 American Psychiatric Association. Diagnostic and Statistical Manual of Mental Disorders (4th edn, revised) (DSM-IV-TR). APA, 2000

11 Harkness J, Pennell BE, Villar A, Gebler N, Aguilar-Gaxiola S, Bilgen I. Translation procedures and translation assessment in the World Mental Health Survey Initiative. In The WHO World Mental Health Surveys: Global Perspectives on the Epidemiology of Mental Disorders (eds RC Kessler, TB Üstün): 91-113. Cambridge University Press, 2008.

12 Kessler RC, Akiskal HS, Angst J, Guyer M, Hirschfeld RM, Merikangas KR, et al. Validity of the assessment of bipolar spectrum disorders in the WHO CIDI 3.0. J Affect Disord 2006; 96: 259-69.

13 Young RC, Biggs JT, Ziegler VE, Meyer DA. A rating scale for mania: reliability, validity and sensitivity. Br J Psychiatry 1978; 133: 429-35.

14 Rush AJ, Trivedi MH, Ibrahim HM, Carmody TJ, Arnow B, Klein DN, et al. The 16-Item Quick Inventory of Depressive Symptomatology (QIDS), clinician rating (QIDS-C), and self-report (QIDS-SR): a psychometric evaluation in patients with chronic major depression. Biol Psychiatry 2003; 54: 573-83.

15 Leon AC, Olfson M, Portera L, Farber L, Sheehan DV. Assessing psychiatric impairment in primary care with the Sheehan Disability Scale. Int J Psychiatry Med 1997; 27: 93-105

16 First MB, Spitzer RL, Gibbon M, Williams JBW. Structured Clinical Interview for DSM-IV Axis I Disorders (Research Version, Non-patient Edition SCID-I/NP). Biometrics Research, New York State Psychiatric Institute, 2002.

17 Kessler RC, Abelson J, Demler O, Escobar Jl, Gibbon M, Guyer ME, et al. Clinical calibration of DSM-IV diagnoses in the World Mental Health (WMH) version of the World Health Organization (WHO) Composite International Diagnostic Interview (WMH-CIDI). Int J Methods Psychiatr Res 2004; 13: 122-39.

18 Haro JM, Arbabzadeh-Bouchez S, Brugha TS, de Girolamo G, Guyer ME, Jin R et al. Concordance of the Composite International Diagnostic Interview Version 3.0 (CIDI 3.0) with standardized clinical assessments in the WHO World Mental Health surveys. Int J Methods Psychiatr Res 2006; 15: 167-80.

19 Haro JM, Arbabzadeh-Bouchez S, Brugha TS, de Girolamo G, Guyer ME, Jin R, et al. Concordance of the Composite International Diagnostic Interview Version 3.0 (CIDI 3.0) with standardized clinical assessments in the WHO World Mental Health Surveys. In The WHO World Mental Health Surveys: Global Perspectives on the Epidemiology of Mental Disorders (eds RC Kessler, TB Üstün): 114-30. Cambridge University Press, 2008.

20 Judd LL, Akiskal HS, Schettler PJ, Endicott J, Leon AC, Solomon DA, et al. Psychosocial disability in the course of bipolar I and II disorders: a prospective, comparative, longitudinal study. Arch Gen Psychiatry 2005; 62 1322-30.

21 Kaya E, Aydemir Ö, Selcuki D. Residual symptoms in bipolar disorder: the effect of the last episode after remission. Prog Neuropsychopharmacol Biol Psychiatry 2007; 31: 1387-92.

22 Akiskal HS, Hantouche EG, Bourgeois ML, Azorin JM, Sechter D, Allilaire JF, et al. Gender, temperament, and the clinical picture in dysphoric mixed mania: findings from a French national study (EPIMAN). J Affect Disord 1998; 50: 175-86.

23 Cassidy F, Yatham LN, Berk M, Grof P. Pure and mixed manic subtypes: a review of diagnostic classification and validation. Bipolar Disord 2008; 10: 131-43

24 Nierenberg AA, Akiskal HS, Angst J, Hirschfeld RM, Merikangas $\mathrm{KR}_{\text {, }}$ Petukhova $M$, et al. Bipolar disorder with frequent mood episodes in the national comorbidity survey replication (NCS-R). Mol Psychiatry 2009; June 30 (Epub ahead of print).

25 Post RM, Luckenbaugh DA, Leverich GS, Altshuler LL, Frye MA, Suppes T, et al. Incidence of childhood-onset bipolar illness in the USA and Europe. Br J Psychiatry 2008; 192: 150-1.
26 Azorin JM, Kaladjian A, Adida M, Hantouche EG, Hameg A, Lancrenon S, et al. Factors associated with rapid cycling in bipolar I manic patients: findings from a French national study. CNS Spectr 2008; 13: 780-7.

27 Cruz N, Vieta E, Comes M, Haro JM, Reed C, Bertsch J, et al. Rapid-cycling bipolar I disorder: course and treatment outcome of a large sample across Europe. J Psychiatr Res 2008; 42: 1068-75.

28 Kupka RW, Luckenbaugh DA, Post RM, Leverich GS, Nolen WA. Rapid and non-rapid cycling bipolar disorder: a meta-analysis of clinical studies. J Clin Psychiatry 2003; 64: 1483-94.

29 Coryell W, Solomon D, Turvey C, Keller M, Leon AC, Endicott J, et al. The long-term course of rapid-cycling bipolar disorder. Arch Gen Psychiatry 2003; 60: $914-20$.

30 Schneck CD, Miklowitz DJ, Calabrese JR, Allen MH, Thomas MR, Wisniewski $\mathrm{SR}$, et al. Phenomenology of rapid-cycling bipolar disorder: data from the first 500 participants in the Systematic Treatment Enhancement Program. Am J Psychiatry 2004; 161: 1902-8.

31 Perlis RH, Ostacher MJ, Patel JK, Marangell LB, Zhang H, Wisniewski SR, et al. Predictors of recurrence in bipolar disorder: primary outcomes from the Systematic Treatment Enhancement Program for Bipolar Disorder (STEP-BD). Am J Psychiatry 2006; 163: 217-24.

32 MacKinnon DF, Zandi PP, Gershon ES, Nurnberger Jr Jl, DePaulo Jr JR. Association of rapid mood switching with panic disorder and familial panic risk in familial bipolar disorder. Am J Psychiatry 2003; 160: 1696-8.

33 Judd LL, Akiskal HS, Schettler PJ, Coryell W, Endicott J, Maser JD, et al. A prospective investigation of the natural history of the long-term weekly symptomatic status of bipolar II disorder. Arch Gen Psychiatry 2003; 60: 261-9.

34 Judd LL, Akiskal HS, Schettler PJ, Endicott J, Maser J, Solomon DA, et al. The long-term natural history of the weekly symptomatic status of bipolar I disorder. Arch Gen Psychiatry 2002; 59: 530-7.

35 Demyttenaere K, Bruffaerts R, Posada-Villa J, Gasquet I, Kovess V, Lepine JP, et al. Prevalence, severity, and unmet need for treatment of mental disorders in the World Health Organization World Mental Health Surveys. JAMA 2004; 291: 2581-90.

36 Alvarez Ariza M, Mateos Alvarez R, Berrios GE. A review of the natural course of bipolar disorders (manic-depressive psychosis) in the pre-drug era. Review of studies prior to 1950. J Affect Disord 2008; 115: 293-301.

37 American Psychiatric Association. Practice guideline for the treatment of patients with bipolar disorder (revision). Am J Psychiatry 2002; 159: 1-50.

38 Ojeda VD, Bergstresser SM. Gender, race-ethnicity, and psychosocial barriers to mental health care: an examination of perceptions and attitudes among adults reporting unmet need. J Health Soc Behav 2008; 49: 317-34.

39 Kessler RC, Brown RL, Broman CL. Sex differences in psychiatric helpseeking: evidence from four large-scale surveys. J Health Soc Behav 1981; 22: 49-64.

40 Tondo L, Baldessarini RJ. Rapid cycling in women and men with bipolar manic-depressive disorders. Am J Psychiatry 1998; 155: 1434-6.

41 Shulman KI, Schaffer A, Levitt A, Herrmann N. Effects of gender and age on phenomenology and management of bipolar disorder: a review. In Bipolar Disorder (eds M May, H Akiskal, JJ Lopez-Ibor, N Sartorius): 359-97. John Wiley \& Sons, 2002

42 Leverich GS, McElroy SL, Suppes T, Keck Jr PE, Denicoff KD, Nolen WA, et al. Early physical and sexual abuse associated with an adverse course of bipolar illness. Biol Psychiatry 2002; 51: 288-97.

43 Garno JL, Goldberg JF, Ramirez PM, Ritzler BA. Impact of childhood abuse on the clinical course of bipolar disorder. Br J Psychiatry 2005; 186: 121-5.

44 Post RM, Leverich GS, Xing G, Weiss RB. Developmental vulnerabilities to the onset and course of bipolar disorder. Dev Psychopathol 2001; 13: 581-98.

45 World Health Organization. The ICD-10 Classification of Mental and Behavioural Disorders: Clinical Descriptions and Diagnostic Guidelines. WHO, 1992. 